\title{
A SIMPLE INTERPRETATION OF THE RICE SPECTRAL INDICES SPACE FOR ASSESSMENT OF HEAVY METAL STRESS
}

\author{
P.Wang, *, F. Huang ${ }^{\mathrm{a}}$, X. N. Liu ${ }^{\mathrm{b}}$ \\ ${ }^{a}$ School of Geographical Sciences, Northeast Normal University, Renmin Street, Changchun, China- wangp666@nenu.edu.cn \\ ${ }^{\mathrm{b}}$ School of Information Engineering, China University of Geosciences, Xueyuan Road, Beijing, China - liuxn@cugb.edu.cn
}

\author{
Commission VII, WG VII/3
}

KEY WORDS: Heavy metal stress, Hyperspectral data, Spectral indices space, Visualization, Rice

\begin{abstract}
:
Heavy metal stress will induce the change of the bio-parameters like chlorophyll, nitrogen and water content of rice. In this paper, we analyzed the traditional spectral index which has strong relationship in general with the three bio-parameters using hyperspectral data acquired by ASD. It is found that some indies do not work well when the heavy metal stress exists, however, some indies still has ability to estimate the above three bio-parameters. A new interpretation is proposed to classify the stress level based on both the physical mechanism analysis and the statistic model after we describe and discuss studies on the expression of spectral indices of rice under heavy metal stress. The 3 -axes spectral indices spaces, which are constructed of 3 spectral indices sensitive to rice's chlorophyll concentration, nitrogen concentration and water concentration respectively, are used to visualize the linkage between heavy metal stress and spectrum of rice canopy.
\end{abstract}

\section{INTRODUCTION}

Heavy metal contamination in soil is going to be worse in China and will damage the food safety. Rice is a main food source widely in the world and its ability to accumulate heavy metal is significantly higher than that of other dry land crops (Kastori et al., 1998). Farmland heavy metal contamination is a global ecological problem and become a threat to human survival and sustainable development due to heavy metal can be induced into food by crop absorption and metabolism, or migrate into the water body.

It is time-consuming to measure the soil quality by traditional chemical methods, and especially the vegetarian coverage makes the soil's spectrum hard to be acquired directly. It is practicable using remote sensing data to indirectly detect the crops' healthy status. However, there are not professional spectral vegetation indices for detection heavy metal contamination or to differentiate between plant diseases and contamination stress on crops. The dynamic, accurate, detection of rice under heavy metal stress shows a great significance and become a practical problem need to be solved urgently. There are some researches identified the heavy metal stress can induce the spectrum response of rice because the change of its health status, including its cellular structure, water content, biochemical composition, pigments content and etc.(Horleret al., 1983; Milton et al., 1989a,b; Guyot et al., 1992; Slatonet al., 2001; Andrew, 2003; Zengin and Munzuroglu, 2005; Meiling Liu, 2011\&2012). Therefore the level of heavy metal stress level can be estimated using remote sensing data.

Many studies have used many types of spectral index to quantitative estimate the chlorophyll content, water content and other parameters about the crops health status separately. Actually the chlorophyll content, water content and other parameters will change simultaneously when the heavy metal stress occurs and the change is very subtle and complicated. Only one parameter's change is not enough to identify the status or level of heavy metal stress the crops undergo. In this paper

\footnotetext{
* Corresponding author. Project 41571405 supported by NSFC
}

we tried to classify the heavy metal stress level considering the change of chlorophyll content, water content and nitrogen content of rice at the same time, which means we found three single spectral index which is sensitive to chlorophyll content, used them to construct a spectral indies space which can show the heavy metal stress level visually.

\section{STUDY AREA AND DATA COLLECTION}

\subsection{Study Area}

Changchun City and Jilin City is two big city in Northeast China. This region is not only the major grain producing areas of Jilin Province,China, but its industrial sector is also relatively complete, which has formed chemical industry, machinery processing industry center mainly based on Jilin Chemical Industrial Company and Changchun automobile manufacturing factory. Considering the pollution status of industrial production, road traffic and other factors on the farmland, the study chooses several rice field samples polluted by heavy metals in the suburbs of Changchun and Jilin. In addition, there are some relatively clean farmland to do the parallel analysis.

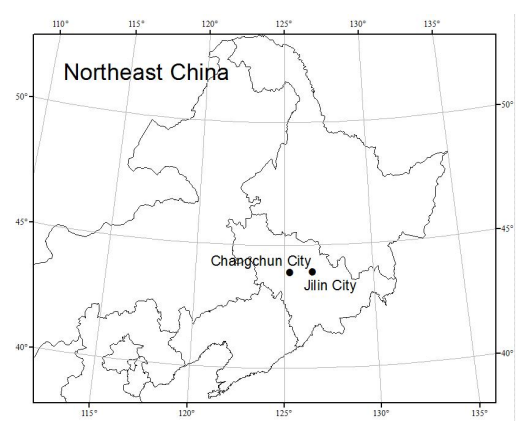

Figure 1. the location of sampling area

The region belongs to temperate continental climate with an average annual rain-fall of 522-615 $\mathrm{mm}$ and an average annual 
temperature of $5.8 \circ \mathrm{C}$. There were 6 sampling areas in three pollution levels in every grow period, and in a similar growth environment, fertilization, water conditions. Pollution lever 0 means the farmland are clean, and lever 2 is more serious than level 1 .

\begin{tabular}{|c|c|c|c|}
\hline Area & Location & Coordinate & $\begin{array}{c}\text { Pollution } \\
\text { Level }\end{array}$ \\
\hline A & Changchun & $125^{\circ} 11^{\prime} \mathrm{E}, 43^{\circ} 51^{\prime} \mathrm{N}$ & 0 \\
\hline B & Changchun & $125^{\circ} 09^{\prime} \mathrm{E}, 43^{\circ} 51^{\prime} \mathrm{N}$ & 0 \\
\hline C & Changchun & $125^{\circ} 10^{\prime} \mathrm{E}, 43^{\circ} 51^{\prime} \mathrm{N}$ & 1 \\
\hline D & Jilin & $126^{\circ} 24^{\prime} \mathrm{E}, 43^{\circ} 59^{\prime} \mathrm{N}$ & 1 \\
\hline E & Jilin & $126^{\circ} 28 \mathrm{E}, 43^{\circ} 57^{\prime} \mathrm{N}$ & 2 \\
\hline F & Jilin & $126^{\circ} 37^{\prime} \mathrm{E}, 43^{\circ} 55^{\prime} \mathrm{N}$ & 2 \\
\hline
\end{tabular}

\subsection{Data Collection}

\subsubsection{Spectrum Measurement}

The FieldSpec 3 spectrometer of United States Analytical Spectral Devices (ASD) company is used for spectral test of field crops. June 2008 to September, July 2009 to September, every 10-20 days, we choose sunny windless weather at 10:30 14:00 GMT to do spectral measurements.15-20 positions were selected and marked from different sampling sites as the spectral acquisition sites before the spectral measurements, with the immediately collection of crop plants and soil samples after the spectral acquisition.Spectral acquisition points require uniform distribution. Spectrometer must be preheating 10-30 minutes after the work. When they perform white calibration before each sample implementation spectral measurement, optimization and acquisition whiteboard reference, white board placed horizontally must fully cover the lens field of view, recapturing the whiteboard reference for every 10-15 minutes. Setting $10^{\circ}$ as field angle, the sensor probe is vertically downward, about 1 meter from the top of the canopy. 10 spectral data is collected for each test point,whose average value is considered as the result of a sample.

\subsubsection{Heavy Metal Contamination Measurement}

After spectral data measured, in the center of each sampling points, $0 \sim 10 \mathrm{~cm}$ depth of the surface soil samples are collected with a plastic shovel, mixing at the scence, quartering about $1 \mathrm{~kg}$ soil samples. Take them back to the laboratory for appropriate treatment including to measure the $\mathrm{As}, \mathrm{Cr}, \mathrm{Zn}, \mathrm{Cu}, \mathrm{Cd}, \mathrm{Pb}$ contents. The test was completed in parallel by the Chinese Academy of Agricultural Sciences and Analytical Center of Northeast Normal University.

According to soil environmental quality standards of China (GB15618-1995) and environmental background values of study area, the evaluation result of soil pollution status were got by ecological rish index(Hakanson, 1980).

\subsubsection{Rice Health Status Measurement}

At the same time of spectral data measurement, the chlorophyll concentration was tested by the SPAD502 (Minolta Corporation, New Jersey, USA) chlorophyll readings, and then the following equation was used to calculate the chlorophyll concentration.

$$
y=0.996 x-1.52
$$

where $\mathrm{y}$ and $\mathrm{x}$ are chlorophyll concentration and SPAD502 chlorophyll reading, respectively.

After spectral data measured, we collected the upper leaves of rice plants, saved in clean envelope (exhaust air), labeled, indicating the location, measurement number, plant parts. Appropriate treatment to get dry weight, moisture content and The nitrogen content of plants are carried in the lab.

\section{METHOD}

\subsection{Spectral Index}

Traditionally spectral indies especially vegetation index like NDVI were used to estimate LAI, chlorophyll content and other parameters of vegetation.In this study 66 vegetation indies (Table 2) were employed to estimate the chlorophyll content, more than 20 other spectral indies used to estimate water content and nitrogen of rice in the study area, where each index derived every parameter as a function of an independent variable.(Zarco-Tejada et al, 2004; Huete,1997; ;Qi, 1994; Penuelas, J., BaRet, F., \& Filella, I. ,1995; Daughtry, 2001; Gitelson et al., 2003; Woodhouse, 1994; Wu et al., 2008, 2009a,b; Yoder, 1995; Dash, 2007;Blackburn, 1998a and 1998b)

Besides the Vegetation index, some spectral index constructed by spectrum shape was used to analyzed the the possibility of estimate the stress level by hyperspectral data. These spectral index were calculated from the continuum removal reflectance spectrum and their indentification are shown in the Figure 2.

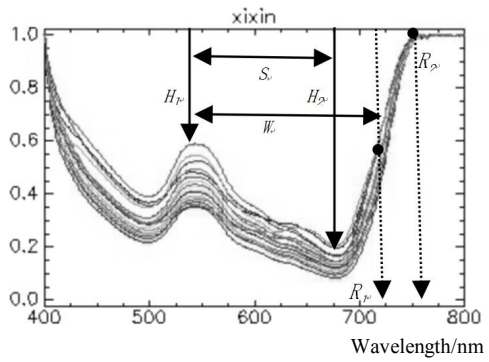

Figure 2. Reflectance spectrum character after continuum removal

\subsection{Correlation Analysis}

The correlation analysis method usually can describe clearly the relationship between spectral index and bio-parameters of rice. In this study, the correlation analysis were used to find most sensitive index to indicate the subtle change of bio-parameters of rice when the heavy metal stress occurs.

\subsection{Spectral Index space}

Spectral Index space can visualize well some relationships between two factors by 2-dimension space. Spectral characteristic parameters sensitive to the changes of 3 biochemical indies--- rice chlorophyll, nitrogen and water content and respond well to heavy metal pollution stress level are selected, pairwise combined to build a three-dimensional spectral index space. We can find that the differences of heavy metal stress level are clearly presented by cluster of samples in feature space, meanwhile the heavy metal pollution stress information has been significantly enhanced. 


\begin{tabular}{|c|c|c|c|}
\hline VI & Formula & VI & Formula \\
\hline $\mathrm{X}_{1}$ & $\mathrm{R}_{800} / \mathrm{R}_{680}$ & $\mathrm{X}_{34}$ & $\left(\mathrm{R}_{550}-\mathrm{R}_{450}\right) /\left(\mathrm{R}_{550}+\mathrm{R}_{450}\right)$ \\
\hline $\mathrm{X}_{2}$ & $\mathrm{R}_{800} / \mathrm{R}_{650}$ & $\mathrm{X}_{35}$ & $\left(\mathrm{R}_{531}-\mathrm{R}_{570}\right) /\left(\mathrm{R}_{531}+\mathrm{R}_{570}\right)$ \\
\hline $\mathrm{X}_{3}$ & $\mathrm{R}_{800} / \mathrm{R}_{550}$ & $\mathrm{X}_{36}$ & $\left(\mathrm{R}_{415}-\mathrm{R}_{435}\right) /\left(\mathrm{R}_{415}+\mathrm{R}_{435}\right)$ \\
\hline $\mathrm{X}_{4}$ & $\mathrm{R}_{750} / \mathrm{R}_{700}$ & $\mathrm{X}_{37}$ & $\left(D_{722}-D_{700}\right) /\left(D_{722}+D_{700}\right)$ \\
\hline $\mathrm{X}_{5}$ & $\mathrm{R}_{750} / \mathrm{R}_{550}$ & $\mathrm{X}_{38}$ & $\left(\mathrm{D}_{722}-\mathrm{D}_{502}\right) /\left(\mathrm{D}_{700}-\mathrm{D}_{502}\right)$ \\
\hline $\mathrm{X}_{6}$ & $\mathrm{R}_{740} / \mathrm{R}_{720}$ & $\mathrm{X}_{39}$ & $\left(\mathrm{R}_{850}-\mathrm{R}_{710}\right) /\left(\mathrm{R}_{850}-\mathrm{R}_{680}\right)$ \\
\hline $\mathrm{X}_{7}$ & $\mathrm{R}_{725} / \mathrm{R}_{702}$ & $\mathrm{X}_{40}$ & $\left(\mathrm{R}_{780}-\mathrm{R}_{710}\right) /\left(\mathrm{R}_{780}-\mathrm{R}_{680}\right)$ \\
\hline $\mathrm{X}_{8}$ & $\mathrm{R}_{710} / \mathrm{R}_{760}$ & $\mathrm{X}_{41}$ & $1 /\left(\mathrm{R}_{695-705}\right)-1 /\left(\mathrm{R}_{750-800}\right)$ \\
\hline $\mathrm{X}_{9}$ & $\mathrm{R}_{705} / \mathrm{R}_{722}$ & $\mathrm{X}_{42}$ & $\left(\mathrm{R}_{800}-\mathrm{R}_{445}\right) /\left(\mathrm{R}_{800}-\mathrm{R}_{680}\right)$ \\
\hline $\mathrm{X}_{10}$ & $\mathrm{R}_{700} / \mathrm{R}_{670}$ & $\mathrm{X}_{43}$ & $\left(\mathrm{R}_{750}-\mathrm{R}_{445}\right) /\left(\mathrm{R}_{705}-\mathrm{R}_{445}\right)$ \\
\hline $\mathrm{X}_{11}$ & $\mathrm{R}_{695} / \mathrm{R}_{670}$ & $\mathrm{X}_{44}$ & $\left(\mathrm{R}_{750}-\mathrm{R}_{706}\right) /\left(\mathrm{R}_{750}+\mathrm{R}_{706}-2 \mathrm{R}_{445}\right)$ \\
\hline $\mathrm{X}_{12}$ & $\mathrm{R}_{695} / \mathrm{R}_{760}$ & $\mathrm{X}_{45}$ & $\left(\mathrm{R}_{734}-\mathrm{R}_{747}\right) /\left(\mathrm{R}_{715}-\mathrm{R}_{720}\right)$ \\
\hline $\mathrm{X}_{13}$ & $\mathrm{R}_{695} / \mathrm{R}_{420}$ & $\mathrm{X}_{46}$ & $\left(\mathrm{R}_{\left.734-\mathrm{R}_{747}\right) /\left(\mathrm{R}_{715}+\mathrm{R}_{726}\right)}\right.$ \\
\hline $\mathrm{X}_{14}$ & $\mathrm{R}_{672} / \mathrm{R}_{550}$ & $\mathrm{X}_{47}$ & $\left(\mathrm{R}_{728}-\mathrm{R}_{720}\right) /\left(\mathrm{R}_{728}+\mathrm{R}_{720}-2 \mathrm{R}_{434}\right)$ \\
\hline $\mathrm{X}_{15}$ & $\mathrm{R}_{657} / \mathrm{R}_{700}$ & $\mathrm{X}_{48}$ & $\left(\mathrm{R}_{728}-\mathrm{R}_{434}\right) /\left(\mathrm{R}_{720}-\mathrm{R}_{434}\right)$ \\
\hline $\mathrm{X}_{16}$ & $\mathrm{R}_{630} / \mathrm{R}_{680}$ & $\mathrm{X}_{49}$ & $\begin{array}{c}{\left[\left(\mathrm{R}_{750^{-}} \mathrm{R}_{705}\right)-0.2\left(\mathrm{R}_{750^{-}}\right.\right.} \\
\left.\left.\mathrm{R}_{550}\right)\right]\left(\mathrm{R}_{750} / \mathrm{R}_{705}\right)\end{array}$ \\
\hline $\mathrm{X}_{17}$ & $\mathrm{R}_{605} / \mathrm{R}_{760}$ & $\mathrm{X}_{50}$ & $\begin{array}{c}{\left[\left(\mathrm{R}_{700-} \mathrm{R}_{670)-0.2\left(\mathrm{R}_{700-}\right.}\right.\right.} \\
\left.\left.\mathrm{R}_{550}\right)\right]\left(\mathrm{R}_{700} / \mathrm{R}_{670}\right)\end{array}$ \\
\hline $\mathrm{X}_{18}$ & $\mathrm{R}_{600} / \mathrm{R}_{680}$ & $\mathrm{X}_{51}$ & $\begin{array}{c}\mathrm{TCARI}=3\left[\left(\mathrm{R}_{700}-\mathrm{R}_{670)-0.2\left(\mathrm{R}_{700^{-}}\right.}\right.\right. \\
\left.\left.\mathrm{R}_{550}\right)^{*}\left(\mathrm{R}_{700} / \mathrm{R}_{670}\right)\right]\end{array}$ \\
\hline $\mathrm{X}_{19}$ & $\mathrm{R}_{430} / \mathrm{R}_{680}$ & $\mathrm{X}_{52}$ & $\begin{array}{c}(1+\mathrm{L})\left(\mathrm{R}_{800}-\mathrm{R}_{670}\right) /\left(\mathrm{R}_{800}+\mathrm{R}_{670}+\mathrm{L}\right), \mathrm{L} \\
=0.16\end{array}$ \\
\hline $\mathrm{X}_{20}$ & $\mathrm{R}_{860} /\left(\mathrm{R}_{550 \times} \mathrm{R}_{708}\right)$ & $\mathrm{X}_{53}$ & $\begin{array}{c}(1+\mathrm{L})\left(\mathrm{R}_{800}-\mathrm{R}_{670}\right) /\left(\mathrm{R}_{800}+\mathrm{R}_{670}+\mathrm{L}\right), \mathrm{L} \\
=0.5\end{array}$ \\
\hline $\mathrm{X}_{21}$ & $\mathrm{R}_{675} /\left(\mathrm{R}_{700} \times \mathrm{R}_{650}\right)$ & $\mathrm{X}_{54}$ & $\begin{array}{c}(1+\mathrm{L})\left(\mathrm{R}_{800}-\mathrm{R}_{670}\right) /\left(\mathrm{R}_{800}+\mathrm{R}_{670}+\mathrm{L}\right), \mathrm{L} \\
=0.2\end{array}$ \\
\hline $\mathrm{X}_{22}$ & $\mathrm{R}_{672} /\left(\mathrm{R}_{550 \times} \mathrm{R}_{708}\right)$ & $\mathrm{X}_{55}$ & TCARI/OSAVI1, $\mathrm{L}=0.16$ \\
\hline $\mathrm{X}_{23}$ & $\mathrm{D}_{715} / \mathrm{D}_{705}$ & $\mathrm{X}_{56}$ & TCARI/OSAVI2, $\mathrm{L}=0.5$ \\
\hline $\mathrm{X}_{24}$ & $\mathrm{D}_{725} / \mathrm{D}_{702}$ & $\mathrm{X}_{57}$ & TCARI/OSAVI3, L=0.2 \\
\hline $\mathrm{X}_{25}$ & $\mathrm{R}_{800}-\mathrm{R}_{550}$ & $\mathrm{X}_{58}$ & $\begin{array}{c}0.5\left\{2 \mathrm{R}_{800}+1-\left[\left(2 \mathrm{R}_{800}+1\right)^{2}-8\left(\mathrm{R}_{800^{-}}\right.\right.\right. \\
\left.\left.\left.\mathrm{R}_{670)}\right)\right]^{1 / 2}\right\}\end{array}$ \\
\hline $\mathrm{X}_{26}$ & $\left(\mathrm{R}_{680}-\mathrm{R}_{550}\right) / \mathrm{R}_{750}$ & $\mathrm{X}_{59}$ & {$\left[\left(\mathrm{R}_{800} / \mathrm{R}_{670}\right)-1\right] /\left(\mathrm{R}_{800} / \mathrm{R}_{670}+1\right)^{1 / 2}$} \\
\hline $\mathrm{X}_{27}$ & $\begin{array}{c}\left(\mathrm{R}_{800^{-}}\right. \\
\left.\mathrm{R}_{680}\right) /\left(\mathrm{R}_{800}+\mathrm{R}_{680}\right)\end{array}$ & $\mathrm{X}_{60}$ & {$\left[\left(\mathrm{R}_{750} / \mathrm{R}_{705}\right)-1\right] /\left(\mathrm{R}_{750} / \mathrm{R}_{705}+1\right)^{1 / 2}$} \\
\hline $\mathrm{X}_{28}$ & $\operatorname{LOG}\left(1 / \mathrm{R}_{737}\right)$ & $\mathrm{X}_{61}$ & $\left(\mathrm{R}_{800}-\mathrm{R}_{670}\right) /\left(\mathrm{R}_{800}+\mathrm{R}_{670}\right)$ \\
\hline $\mathrm{X}_{29}$ & $1 / \mathrm{R}_{700}$ & $X_{62}$ & $\left(\mathrm{R}_{800}-\mathrm{R}_{635}\right) /\left(\mathrm{R}_{800}+\mathrm{R}_{635}\right)$ \\
\hline $\mathrm{X}_{30}$ & $1 / \mathrm{R}_{670}$ & $\mathrm{X}_{63}$ & $\left(\mathrm{R}_{774}-\mathrm{R}_{677}\right) /\left(\mathrm{R}_{774}+\mathrm{R}_{677}\right)$ \\
\hline $\mathrm{X}_{31}$ & $1 / \mathrm{R}_{550}$ & $\mathrm{X}_{64}$ & $\left(\mathrm{R}_{750}-\mathrm{R}_{705}\right) /\left(\mathrm{R}_{750}+\mathrm{R}_{705}\right)$ \\
\hline $\mathrm{X}_{32}$ & $1 / \mathrm{R}_{530}$ & $\mathrm{X}_{65}$ & $\left(\mathrm{R}_{750}-\mathrm{R}_{550}\right) /\left(\mathrm{R}_{750}+\mathrm{R}_{550}\right)$ \\
\hline $\mathrm{X}_{33}$ & $1 / \mathrm{R}_{450}$ & $\mathrm{X}_{66}$ & $\left(\mathrm{R}_{570}-\mathrm{R}_{670}\right) /\left(\mathrm{R}_{570}+\mathrm{R}_{670}\right)$ \\
\hline
\end{tabular}

Table 2. Veagetation Indies used to estimate chlorophyll content

\section{RESULTS AND DISCUSSION}

\subsection{Sensitive Spectral Indies}

In the study, some indies do not show good relationship with the bio-parameters while they can do good job normally (Figure 3). It seems the unhealthy rice under heavy metal stress has different sensitive spectral indies from that of healthy rice.

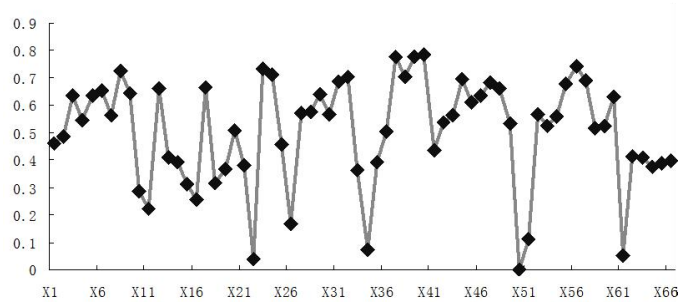

Figure 3. Goodness of fitting between rice chlorophyll and vegetation indies

\subsubsection{Chlorophyll Sensitive Index}

Vegetation chlorophyll content is closely related to its health status, which is one of the most important indexes to indicate plant nutrition stress, photosynthetic capacity and development status (Demetriades-Shah, 1990). Typically, after heavy metals (pollution) stress, the growth of green crop is stimulated or inhibited, resulting in the changes of chloroplast structure and leaf color.Through the analysis of the leaves and canopy spectra of rice and other vegetation, domestic and foreign scholars have confirmed that spectral characteristics and biochemical parameters were significantly correlated.It is feasible to establish the chlorophyll content retrieval model by hyperspectral remote sensing data.

The study area shows a negative correlation of the chlorophyll content and the degree of heavy metal pollution. But it is noteworthy that in different growth stage the impact of heavy metal pollution stress in chlorophyll content is different. Firstly, this paper uses vegetation index to extract the chlorophyll content information.then selects the vegetation index sensitive to the chlorophyll content, further selects the sensitive parameters to heavy metal pollution stress from last step. The vegetation index are more sensitive to the spectral changes than single band, conducive to the eliminate the effects of soil brightness, atmospheric and topographic.

The best fitting degree is X24(D725/D702).D725 represents the first derivative of reflectance spectra in $725 \mathrm{~nm}$ wavelength. D702 represents the first derivative of reflectance spectra in 702nm wavelength. X40(R780-R710)/(R780-R680):R780-R710 represents the sum of vegetation spectral reflectance from $780 \mathrm{~nm}$ to $680 \mathrm{~nm}$ band. These high fitting degree of vegetation index are selected to inversion chlorophyll content, as shown in figure 3 .

Here, the goodness of fit refers to the square of the correlation coefficient. Rice canopy chlorophyll content is significantly correlated with the spectral information, moreover the fitting degree of chlorophyll content and spectral information reaches maximum in the red band(figure 4), which is closely related to the chlorophyll strong absorption of blue and red light. The fitting degree of the original spectrum and the chlorophyll 
content was relatively stable before $710 \mathrm{~nm}$, and then decreased rapidly, and the correlation was almost zero at $750 \mathrm{~nm}$. In comparison, the fitting degree of derivative spectra and chlorophyll content is better than the original spectra.The maximum goodness of fit between original spectrum and chlorophyll content of rice is 0.53 ; the maximum goodness of fit between the first derivative spectra and chlorophyll content of rice is 0.64 ; the maximum goodness of fit between second order derivative spectra and chlorophyll content of rice is 0.72 ; this shows that the first derivative spectra is more effective to the inversion of chlorophyll content. The fitting degree of first derivative spectrum and chlorophyll content reaches the maximum at $730-760 \mathrm{~nm}$ band, which is consistent with the conclusions of Changshan $\mathrm{Wu}$ et al. The fitting degree of other bands such as $540-560 \mathrm{~nm}, 680-700 \mathrm{~nm}$ are better as well.

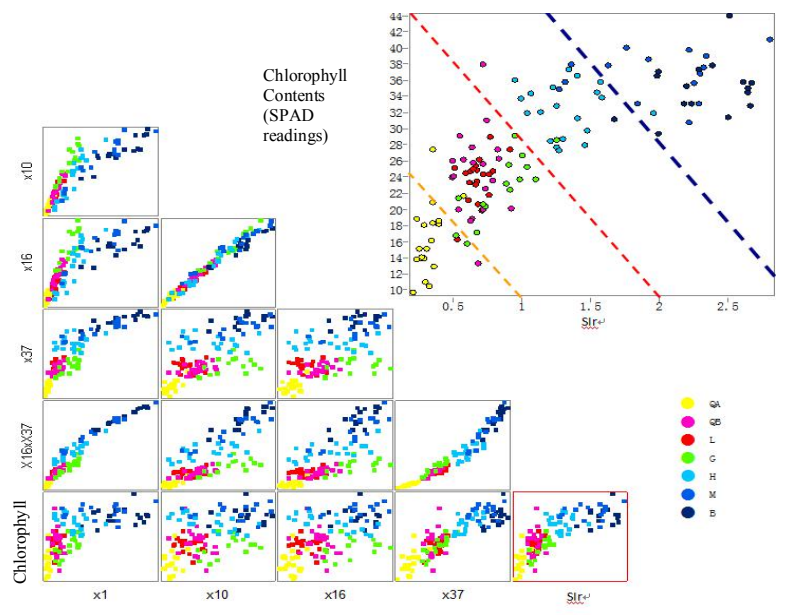

Figure 4. Correlation between the degree of pollution stress and vegetation index, chlorophyll content in Rice

\subsubsection{Nitrogen Sensitive Index}

When rice was affected by heavy metal stress, heavy metals would hinder the nitrogen absorption, and nitrogen deficiency would cause the inadequate development of crop leaf, smaller mesophyll cells, leaf senescence, lower chlorophyll, water content and protein content. This series of biological physical and chemical changes will inevitably bring reflection spectrum response.

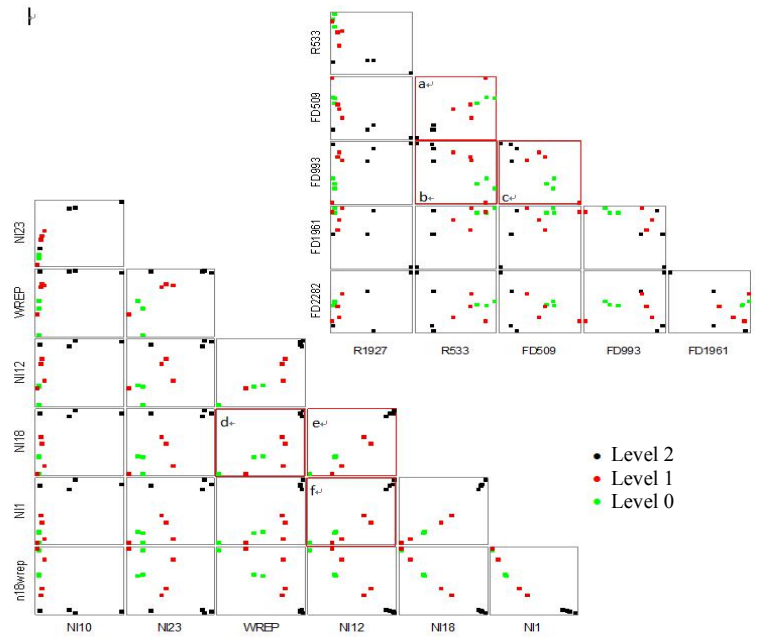

Figure 5. Rice nitrogen sensitive index matrix
Two spectral indices are selected to establish the inversion model,whose goodness of fit to nitrogen content are better than others. NI10 is the best spectral index to inverse nitrogen content of rice, determination coefficient 0.592 ; followed by NI23, determination coefficient is 0.459 . In figure $4, \mathrm{~N} 10$ is $R_{1927} / R_{533}$, where $R_{1927}$ is the reflactance at wavelength. $1927 \mathrm{~nm}$.

\subsubsection{Water Content Sensitive Index}

Moisture content of crops is often used to measure the health status.Stressed by heavy metals contaminated, leaf cell structure and moisture absorption ability of crops change, accordingly moisture content of crops varying.Traditional method to measure crop water content by individual plant in small area is low efficiency, one-sided and destruction. For real-time monitoring and diagnosing crop moisture content, remote sensing technology not only improve the efficiency, plays a guiding role on crop growth management and water control, but also has an important implications for the plant cover of flammable and forest fire monitoring by remote sensing. The study has carried on correlation analysis between reflectance of $700-700 \mathrm{~nm}, 1350-1810 \mathrm{~nm}$ and 1900-2400 nm band and water content of rice.

The inversion of leaf water content can use canopy (or blade) spectral reflectance, but the spectral reflectance is easily affected by light condition and the operation of spectral acquisition process.Therefore, differential calculation and continuum removed method can be used to deal with the original reflection spectra, construction of all kinds of spectral parameters such as moisture absorption depth and water remote sensing indices, in order to improve the calculation precision of the moisture content changes under heavy metal pollution stress, and further find spectral parameters that are sensitive to heavy metal pollution stress.

WI2(R950/R900) is the best moisture spectral index to the inversion effect of rice, whose determination coefficient of quadratic polynomial fitting is 0.616 ; followed by WI3(R810/R640), whose determination coefficient of quadratic polynomial fitting is 0.593 .

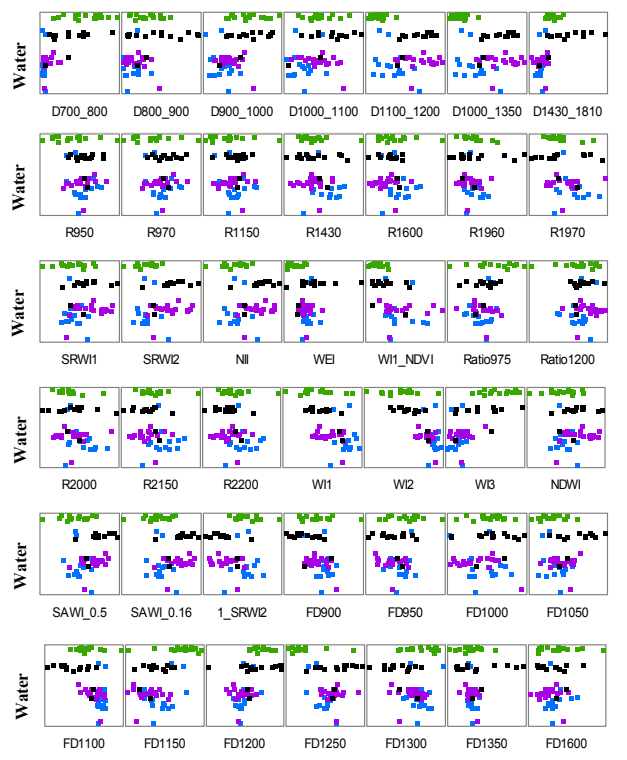

Figure 6. Correlation between rice water contend and its spectral index 
Similar to nitrogen sensitive index and Chlorophyll Sensitive Index, water content sensitive index shows much lower correlation degree with water content when the rice undergo the heavy metal stress, however, they all do this well when the crops are healthy.

\subsection{Spectral Index Space}

Based on the above analysis, three types of index can used to create the three axes of Index Space, which means we integrate the change of chlorophyll content, water content and nitrogen change of the rice under heavy metal stress (Figure 6.). It is obviously that the samples with different pollution level locates farther than those points with similar pollution level. In figure 6 , the green points which locates upper in the graph come from the clean farmlands, while the dark points which locate lower in the space come from the polluted farmlands with level 2. The middle points in the space in red and blue come from the subtle pollution stress rice lands.
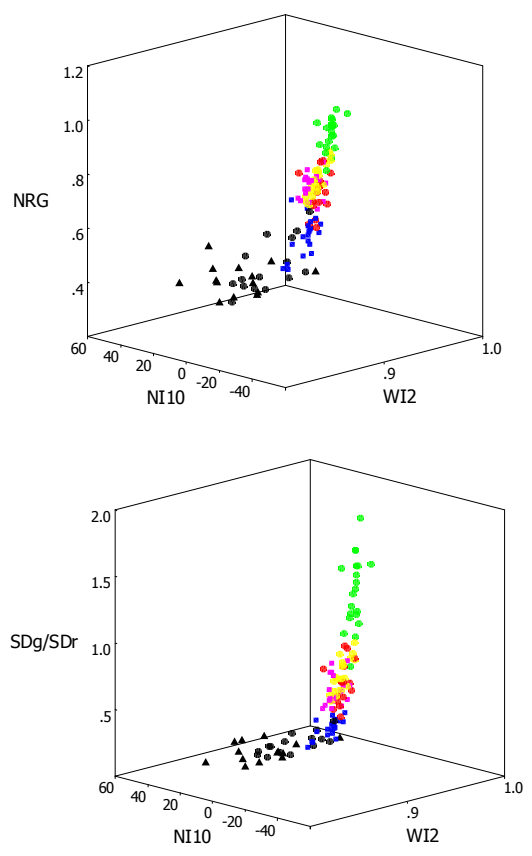

Figure 7. Two Typical Spectral Index Space

In figure 7, two indices has not mentioned above, they are NRG and $\mathrm{SDg} / \mathrm{SDr}$. The two indices are both sensitive to the chlorophyll content. SDg refers the abosorption area in green bands and SDr refers the abosorption area in red bands. The ration of $\mathrm{SDg}$ and SDr. will decrease when the chlorophyll contens decrease. NRG is normalized green peak reflectance, which is calculated by reflectance spectrum after continuum removal.

Actually, chlorophyll, nitrogen and water conternt can reflect the healthy status of plant. So 3 spectral indies sensitive to the 3 bio-parameters respectively can describe the healthy status of rice. In addition, the 3 spectral indies we got used the information from visible to near Infrared bands, which means the 3 indies used most information of the whole spectrum. In figure 8 , it can be found the classification result of heavy metal stress level by the 3 indies is better than single index.

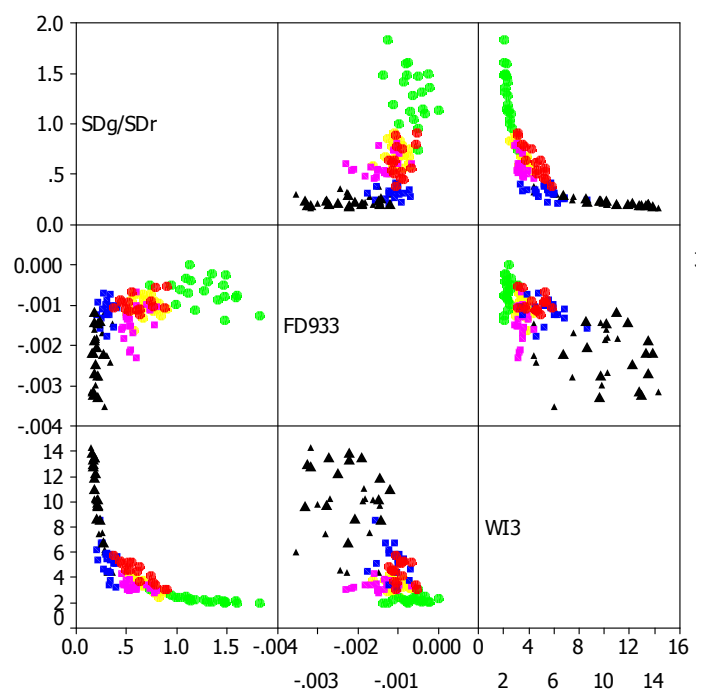

Figure 8. Heavy metal stress level evaluation model

This thesis has comprehensively analyzed rice spectral response characteristics to heavy metal pollution stress from three viewpoints of the change of chlorophyll, nitrogen and water content respectively. At present, the domestic and foreign research on crop heavy metal pollution stress monitoring by remote sensing mainly selects leaf area index, chlorophyll concentration, $\mathrm{N}, \mathrm{P}$ and other nutrients content moisture status and other agronomic parameters.and then uses remote sensing data to calculate their quantity target and changes, as the indicator of pollution degree and status. But in fact,the crops' physiological and ecological response to heavy metals stress is very weak, small and unstable reflecting in the changes of these agronomic parameters. Many studies mainly rely on color properties of crops growth, for example they select pigment changes as the major evidence of crop pollution stress, despite its reasonable side. However, there are many factors that affect the changes of pigment, such as light, water and fertilizer change,. The impact of these factors on crop pigment is huge, so the small changes caused by pollution stress are likely to be covered by it. This paper quantitatively extracts crop information stressed by contamination from remote sensing data and does the corresponding analysis. This paper effectively enhances and calculates the remote sensing spectral weak effect on crops stressed by heavy metal, providing a rapid and reliable method for monitoring crop heavy metal pollution stress by satellite remote sensing.But satellite remote sensing data suffers more influence factor than ground test data. Follow-up works can carry out experiments and studies on satellite hyperspectral remote sensing data, for rapidly monitoring crops' information about heavy metal pollution stress. In addition, other stress factors such as water, fertilizer and light can also make crops produce similar physiology characteristic and spectral response to heavy metal stress. Therefore, we should actively explore the small difference of various stress factors in spectral response, not only determine crop stress level, but also the causes of stress.

\section{CONCLUSIONS}

The study has analyzed the distribution of heavy metal elements in soil and crops based on the experimental data, and studied heavy metal pollution stress effect mechanism to the change of 
crops' chlorophyll, nitrogen and water content. The study has comprehensively analyzed crop spectral reflectance characteristics, researched and verified the response relationship of crops biochemical parameter changes under spectral indices and heavy metal contamination stress, established the hyperspectral inversion model about the small change of crop chlorophyll, nitrogen and moisture content.The results shows that the many conventional remote sensing indexes, which is used for the retrieval of crop physiological indexes, is severely decreased in the accuracy under the heavy metal pollution stress.

The best the goodness of fit is X24 (D725/D702) in chlorophyll. NI10 is the best spectral index to inverse nitrogen content in rice, determination coefficient 0.592 . WI2(R950/R900) is the best moisture spectral index to inverse moisture content in rice, quadratic polynomial fitting determination coefficient 0.616 .

The plots with different pollution levels have better clustering characteristics in the $3 \mathrm{~d}$ spectral index space. Because the spectral index space is constructed by the three indies which are sensitive to the 3 key bio-parameters respectively, the pollution level is easily expressed by the points location cluster feather. SVM is a good non-linear classification method and do a good job here to classify the samples into its pollution level with a high correct degree.

The heavy metal stress level is identified well in this paper, but this work need to calculate a big deal of spectral indies and their relationship with bio-parameters of rice. The further work need to focus on the spectral index which are suitable for most plants and stable with the environments change. In addition, it is more important that inducing this method to remote sensing images, which will bring much more applications.

\section{ACKNOWLEDGEMENTS}

The authors would like to acknowledge the Project 41571405 supported by National Natural Science Foundation of China.

\section{REFERENCES}

Andrew C. Schuerger, Gene A. Capelle, John A. Di Benedetto, Chengye Mao, Chi N. Thai, Mark D. Evans, Jeff T. Richards, Tim A. Blank, Elizabeth C. Stryjewski. 2003. Comparison of two hyperspectral imaging and two laser-induced fluorescence instruments for the detection of zinc stress and chlorophyll concentration in bahia grass (Paspalum notatum Flugge.)[J]. Remote Sensing of Environment, 84 : pp. $572-588$

Blackburn, G. A. 1998a. Quantifying chlorophylls and carotenoids at leaf and canopy scales; An evaluation of some hyperspectral approaches. Remote Sensing of Environment, 66(3), pp. 273-285.

Blackburn, G. A. 1998b. Spectral indices for estimating photosynthetic pigment concentrations: A test using senescent tree leaves. International Journal of Remote Sensing,19(4), pp. 657-675.

Guyot, G., Baret, F., Jacquemoud, S., 1992. Imaging spectroscopy for vegetation stud-ies. In: Imaging Spectroscopy: Fundamentals and Prospective Applications, vol.2, pp. 145-165.

Gitelson, A.A., Gritz, Y., Merzlyak, M.N., 2003. Relationships between leaf chlorophyll content and spectral reflectance and algorithms for non-destructive chlorophyll assessment in higher plant leaves. J. Plant Physiol. 160, pp.271-282.

Dash, J., Curran, P.J., 2007. Evaluation of the MERIS terrestrial chlorophyll index(MTCI). Adv. Space Res. 39 (1), pp.100-104.

Daughtry, C.S.T., 2001. Discriminating crop residues from soil by shortwave infraredreflectance. Agron. J. 93 (1), pp.125-131.

Demetriades-Shah T H, Strven M D, Clark J A. 1990. High resolution derivative spectra in remote sensing [J]. Remote Sensing of Environment, 33(1): pp. 55-64

Horler, D.N.H., Dockray, M., Barber, J., 1983. The red edge of plant leaf reflectance.Int. J. Remote Sens. 4 (2), pp. 273-288.

Huete, A.R., Liu, H.Q., vanLeeuwen, W.J.D., 1997. The use of vegetation indicesin forested regions: issues of linearity and saturation. In: InternationalGeoscience and Remote Sensing Symposium, Proceedings. Igarss '97. Vols.I-IV: Remote Sensing

Kastori, R., Plesnicar, M., Sakac, Z., Pankovic, D., ArsenijevicMaksimovic, I., 1998. Effect of excess lead on sunflower growth and photosynthesis. J. Plant Nutr. 21(1), pp. 75-85.

Lars Hakanson. An ecological rish index for aquatic pollution control: a sedimentological approach $[\mathrm{J}]$. Water Research, 1980, 14: pp. 975-1001.

Liu, M.L., Liu, X.N., Ding, W.C., Wu, L., 2011. Monitoring stress levels on rice withheavy metal pollution from hyperspectral reflectance data usingwavelet-fractal analysis. Int. J. Appl. Earth Obs. Geoinf. 13 (2), pp. 246-255.

Liu, M.L., Liu, X.N., Li, J., Li, T., 2012. Estimating regional heavy metal concentrationsin rice by scaling up a field-scale heavy metal assessment model. Int. J. Appl.Earth Obs. Geoinf. 19, pp. 12-23.

Milton, N.M., Ager, C.M., Eiswerth, B.A., Power, M.S., 1989a. Arsenic-induced andselenium-induced changes in spectral reflectance and morphology of soybeanplants. Remote Sens. Environ. 30 (3), pp. 263-269.

Qi, J., Chehbouni, A., Huete, A.R., Kerr, Y.H., Sorooshian, S., 1994. A modified soiladjusted vegetation index. Remote Sens. Environ. 48 (2), pp. 119-126.

Ruan, W. ,YAN, C. Y. ,NIU Z.. 2003. Comparison of spectral statistical parameters for remote sensing of plant biochemical components, Remote sensing technology and Application 18 (4) :pp. 233 - 236.

Slaton, M.R., Hunt, E.R., Smith, W.K., 2001. Estimating nearinfrared leaf reflectancefrom leaf structural characteristics. Am. J. Bot. 88 (2), 278-284.

Woodhouse, R., Heeb, M., Berry, W., Hoshizaki, T., Wood, M., 1994. Analysis ofremote reflection spectroscopy to monitor plant health. In: MacElroy, R.D.,et al. (Eds.), Life Sciences and Space Research Xxv. Advances in Space Research, pp. 199-202.

Wu, C., et al., 2009a. Remote estimation of gross primary production in wheatusing chlorophyll-related vegetation indices. Agric. For. Meteorol. 149 (6-7), pp.1015-1021.

Wu, C., Niu, Z., Tang, Q., Huang, W., 2008. Estimating chlorophyll content from hyper-spectral vegetation indices: 
modeling and validation. Agric. For. Meteorol. 148(8-9), pp. $1230-1241$

Wu, M., Zhang, W., Wang, X., Luo, D., 2009b. Application of MODIS satellite data in estimation water quality parameters of Chaohu Lake in China. Environ. Estim.Assess. 148, pp. 255264.

Yoder, B.J., Pettigrewcrosby, R.E., 1995. Predicting nitrogen and chlorophyll contentand concentrations from reflectance spectra (400-2500 nm) at leaf and canopyscales. Remote Sens. Environ. 53 (3), pp. 199-211.

Zarco-Tejada, P.J., Miller, J.R., Morales, A., Berjon, A., Aguera, J.. 2004. Hyperspectral indices and model simulation for chlorophyll estimation in open-canopy tree crops. Remote Sensing of Environment. 90(4), pp. 463-476.

Zengin, F.K., Munzuroglu, O., 2005. Effects of some heavy metals on content of chloro-phyll, proline and some antioxidant chemicals in bean (Phaseolus vulgaris L.)seedlings. Acta Biol. Crac. Ser. Bot. 47 (2), pp. 157-164. 